\title{
Research on the Deviation Sensing of V-groove Weld Seam based on a Novel Two Channel Acoustic Sensor
}

Yanfeng Gao ( $\nabla$ gyf_2672@163.com )

Shanghai University of Engineering Science https://orcid.org/0000-0002-5152-6091

Jianhua Xiao

Shanghai University of Engineering Science

Genliang Xiong

Shanghai University of Engineering Science

Hua Zhang

Shanghai University of Engineering Science

\section{Research Article}

Keywords: Weld seam tracking, Acoustic sensor, Binaural effect, V-groove weld seam, Sound signals

Posted Date: September 7th, 2021

DOI: https://doi.org/10.21203/rs.3.rs-863476/v1

License: (c) (i) This work is licensed under a Creative Commons Attribution 4.0 International License. Read Full License

Version of Record: A version of this preprint was published at The International Journal of Advanced Manufacturing Technology on January 16th, 2022. See the published version at https://doi.org/10.1007/s00170-021-08454-9. 


\title{
Research on the deviation sensing of V-groove weld seam based on a novel two channel acoustic sensor
}

\author{
Yanfeng $\mathrm{Gao}^{1 *}$, Jianhua Xiao ${ }^{2 *}$, Genliang Xiong ${ }^{1}$, Hua Zhang ${ }^{1}$ \\ 1. School of Mechanical and Automotive Engineering, Shanghai University of Engineering Science, Shanghai 201620, China \\ 2.School of Chemistry and Chemical Engineering, Shanghai University of Engineering Science, Shanghai 201620, China \\ *Corresponding authors: Yanfeng Gao(E-mail:gyf_2672@163.com); Jianhua Xiao(E-mail:xjh3500021002@163.com)
}

\begin{abstract}
It is essential to sense the deviation of weld seam real-timely in robotic welding process. However, welding process always accompanied with high temperature, strong arc light and background noises, which significantly affects the application of sensors. In this study, a novel acoustic sensor was developed. This sensor consists of two microphones. Based on the sound signals collected by these two microphones, the deviation of weld seam was detected. The frequency response of the developed acoustic sensor was studied through simulation method firstly, and then the sensing performance of it was analyzed with experiments. The experimental results show that the developed acoustic sensor has a linear property for the deviation detection of V-groove weld seam. This research provides a novel method for weld seam tracking.
\end{abstract}

Keywords: Weld seam tracking; Acoustic sensor; Binaural effect; V-groove weld seam; Sound signals

\section{Introduction}

In robotic welding process, real-time seam tracking is essential for eliminating the welding path errors caused by heat-induced distortions of weld part. However, welding is a complicated physical process. It usually accompanied with high temperature, strong arc light and background noises, which significantly affects the application of sensors. For sensing the weld seam position real-timely, tactile sensors, arc sensors and vision sensors have been developed in the past few years.

Presern et al. [1] developed a tactile sensor to find and track three-dimensional trajectory of weld seam. Lei et al. [2] improved the structure of it to measure displacement and angular errors for tracking super narrow gap weld seam. Kim et al. [3] built a mathematical model of rotating arc sensor, and Shi et al.[4] improved this model for weld seam detection. Kodama et al. [5] studied the arc sensor sensitivity in short circuiting metal gas welding process. Gao et al. [6] adopted rotating arc sensor to detect the deviation and inclination of welding torch simultaneously.

Vision sensors also are extensively adopted in sensing the deviation of weld seam.There are two types of vision sensing methods: active vision and passive vision. In active vision, a low power laser is used to generate light stripes, and according to the projection images of light stripes on weld seam the tracking errors are obtained. Chen et al. [7] and Qin et al. [8] utilized active vision sensors to measure the deviations of weld torch. Wu et al. [9] adopted modified Hough-transform and Jia et al. [10] employed Kalman filter to extract the feature point of weld seam when the laser stripe was disturbed by heavy arc and welding splash. In passive vision, welding arc itself is used as the light source. Lee et al. [11] presented a passive vision sensor system in pulse laser welding process. For capturing clear images of weld pool, Chen et al. [12] and Xu et al. [13] adopted a narrow band optical filter with central wave length $630 \mathrm{~nm}$ and $660 \mathrm{~nm}$ respectively.

Arc sound signals contain abundant information of welding process, such as the stability and splash of it. Therefore, arc sound signals have been adopted recently to monitor welding process. Song et al. [14] utilized arc sounds signals to predict the penetration states of weld bead. Lv et al. [15] adopted arc sound signals to identify the penetration states in GTAW process. Zhang et al. [16] analyzed the frequency components of arc sounds and identified penetration states of aluminum alloy weld bead. Gao et al. [17] based on the human welder subjective assessments on arc sounds to identify the penetration states. Lan et al. [18] studied the 
correlation of arc sound with arc position in narrow gap welding process. The offset distance from arc to sidewall of weld seam was detected according to arc sounds. Liu et al. [19] developed a swing arc sound sensor to detect the arc deviation for narrow gap weld seam tracking. The short-time energy of arc sound signals was selected as the feature for arc deviation sensing. Lv et al. [20] adopted a dual-microphone array to monitor the welding path in pulse metal-gas welding process.

Based on those previous studies, this paper develops a novel acoustic sensor to detect the V-groove weld seam position. This sensor consists of two microphones and based on the sound signals collected by these two microphones to sense the deviation of weld seam. Firstly, the structure of the developed acoustic sensor and the basic principle of it are explained. Secondly, with numerical simulation methods, the sensing properties of the developed sensor are analyzed. Subsequently, the sensing properties of the developed sensor are tested through a series of experiments, and the optimal frequency of it is acquired. Finally, some welding experiments are implemented to study the sensing capabilities of the developed acoustic sensor.

\section{An acoustic sensor design}

An acoustic sensor was designed in this study for sensing weld-seam position based on sound signals. The structure of it is shown in Fig.1, and the product of it is shown in Fig.2.

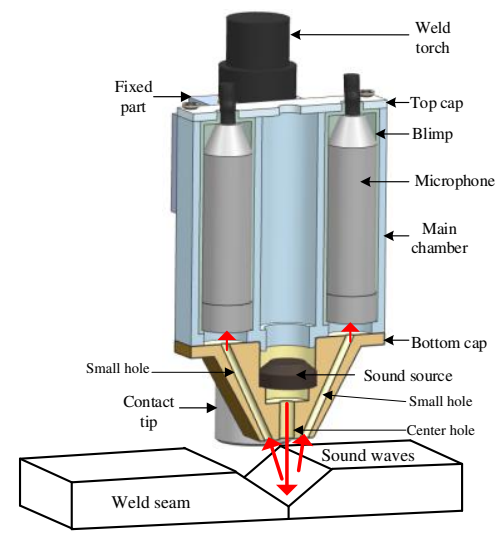

Fig.1 The structure of designed acoustic sensor

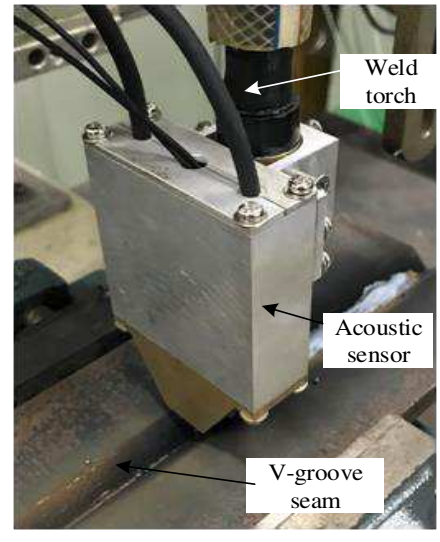

Fig.2 The picture of the acoustic sensor

As shown in Fig.1, the designed acoustic sensor consists of top cap, blimp, microphone, main chamber, bottom cap, sound source and fixed part. The sound source is a RY-LB woofer, and it is mounted in the center hole of the bottom cap to generate sound waves. Two microphones are packed in the two cavities that located on the two sides of the center hole symmetrically. In the interior of bottom cap, there are two small holes with diameter of $2 \mathrm{~mm}$ and a center hole with diameter of $8 \mathrm{~mm}$.As shown in Fig.2, during welding process the acoustic sensor is mounted on the front of weld torch to detect the deviation of weld seam.

In sensing process, as shown with the red arrows in Fig.1, sound waves are generated by sound source firstly, and then propagate downward within the center hole and arrive at the surface of weld seam. Subsequently, these sound waves are reflected by weld seam and received by two microphones via two small holes, respectively. When the designed acoustic sensor locates at the center of weld seam, the propagation paths of sound waves that received by two microphones are symmetrical. If the the acoustic sensor locates at the right or left of the weld seam, the propagation paths of sound waves are no longer symmetrical. Therefore, the sound pressures that received by two microphones are different. Based on the differences of sound pressures of two microphones, the deviation of acoustic sensor is obtained.

\section{Sensing property analysis with numerical simulation}

\subsection{Mathematical model}

To simulate the transmitting process of sound waves in the designed acoustic sensor, the governing 
equations are given as follows.

Continuity:

$$
\frac{\partial\left(\rho_{0}+\rho^{\prime}\right)}{\partial t}=-\left(\rho_{0}+\rho^{\prime}\right) \nabla v
$$

Motion:

$$
\left(\rho_{0}+\rho^{\prime}\right)\left(\frac{\partial}{\partial t}+v \cdot \nabla\right)=-\nabla\left(P_{0}+P^{\prime}\right)
$$

State:

$$
\frac{P}{P_{0}}=\left(\frac{\rho}{\rho_{0}}\right)^{\gamma}
$$

where, $P_{0}, \rho_{0}$ are the sound pressure and air density in stationary state, respectively. $P^{\prime}, \rho^{\prime}$ are the variation of sound pressure and air density caused by outside disturbance, respectively. $v$ is the vibration velocity of particle. $\gamma$ is a constant and equal to 1.402 . From the governing equations, the acoustic wave can be expressed as equation (4).

$$
\nabla^{2} P^{\prime}-\frac{1}{c^{2}} \frac{\partial^{2} P^{\prime}}{\partial t^{2}}=0
$$

where, $\nabla$ is a Lagrange operator. $\nabla^{2}=\frac{\partial^{2}}{\partial x^{2}}+\frac{\partial^{2}}{\partial y^{2}}+\frac{\partial^{2}}{\partial z^{2}}$. $c$ is the velocity of sound waves, $c=\sqrt{\frac{\gamma P_{0}}{\rho_{0}}}$. Based on Fourier transform, an arbitrary vibration could be expressed as the integration of series simple harmonic oscillations. Therefore, the variation of sound pressure is expressed as equation (5).

$$
P^{\prime}=P(x, y, z) \cdot e^{j \alpha x}
$$

Substituting the expression of $P^{\prime}$ into equation (4), a Helmholtz equation is obtained.

$$
\nabla^{2} P(x, y, z)-k^{2} P(x, y, z)=0
$$

where, $k=\omega / c, \omega=2 \pi f / c$.

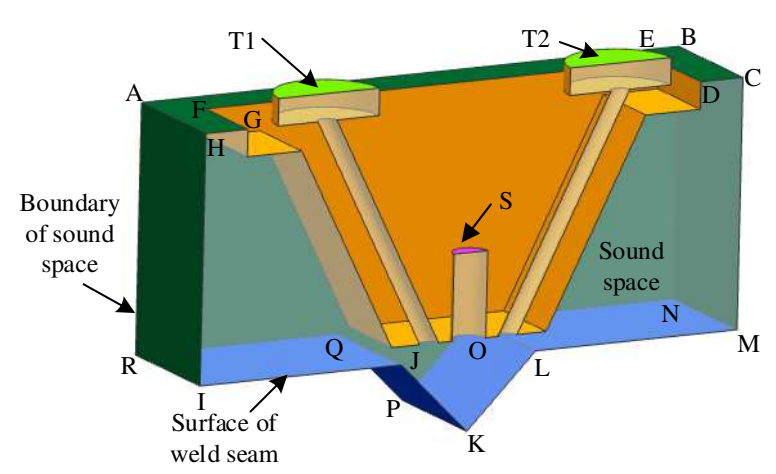

(a) Boundaries of model

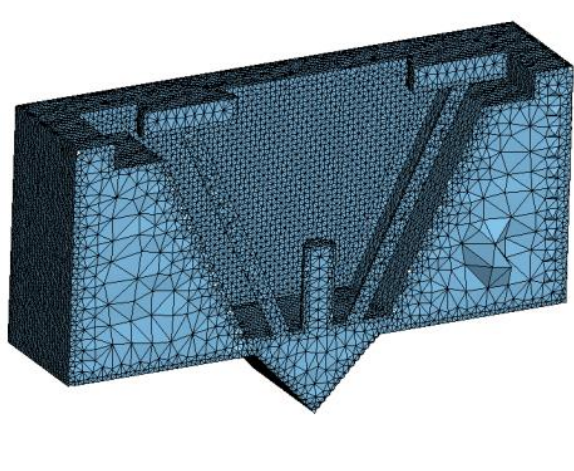

(b) Mesh generating

Fig. 3 The finite elementary model of designed sensor

Fig.3a shows the finite elementary model of the designed acoustic sensor. In Fig.3a, S is the inlet boundary of sound source. $T_{1}$ and $T_{2}$ are the outlet boundary of sound waves. The faces of AHRI, ARNB, BCMN and AHGFEDCB are the boundaries of sound space. In these boundaries, there are no reflections when sound waves traverse through them. The faces of RIJQ, JQPK, PKLO and LONM are the surfaces of weld seam. They are assumed as fully reflecting surfaces. On these surfaces, the sound waves are totally reflected and there are no energy losses. The interior walls of sensor are supposed as fully reflecting surfaces too. In the numerical simulating process, tetrahedral mesh with size of $0.6 \mathrm{~mm}$ is adopted. The geometry model after mesh generating is shown in Fig.3b. The numerical model boundary conditions of the designed acoustic sensor are listed in Tab.1. The distance from the bottom of sensor to the top surface of weld seam is set as $2 \mathrm{~mm}$ in the simulation process. 
Tab.1 Boundary conditions

\begin{tabular}{cccccc}
\hline Boundary & Pressure P/Pa & Impedance $\mathrm{Zp}\left(\mathrm{Kg} / \mathrm{m}^{2} / \mathrm{s}\right)$ & Density & $\rho\left(\mathrm{Kg} . \mathrm{m}^{-3}\right)$ & Velocity c $\left(\mathrm{m} . \mathrm{s}^{-1}\right)$ \\
\hline $\mathrm{S}$ & 1 & - & 1.225 & 340 \\
$\mathrm{~T}_{1}$ & - & 416.5 & 1.225 & 340 \\
$\mathrm{~T}_{2}$ & - & 416.5 & 1.225 & 340 \\
Sound space & - & 416.5 & 1.225 & 340 \\
Weld seam surface & - & - & - & - \\
\hline
\end{tabular}

\subsection{Results and discussion}

\subsubsection{The influence of sound source frequency}

The transmitting process of sound wave in a local space is shown in Fig.4a. The sound waves are generated by sound source on the inlet boundary S firstly. Then they propagate downward within a center hole and arrive at the surfaces of weld seam and are reflected by these surfaces. Afterward, the reflected sound waves enter two long small holes and received by two microphones at the outlet boundary $\mathrm{T}_{1}$ and $\mathrm{T}_{2}$.

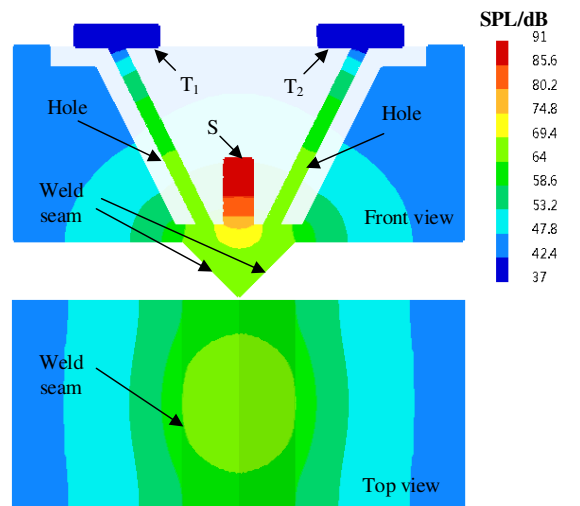

(a) Sound source frequency is $2001 \mathrm{~Hz}$

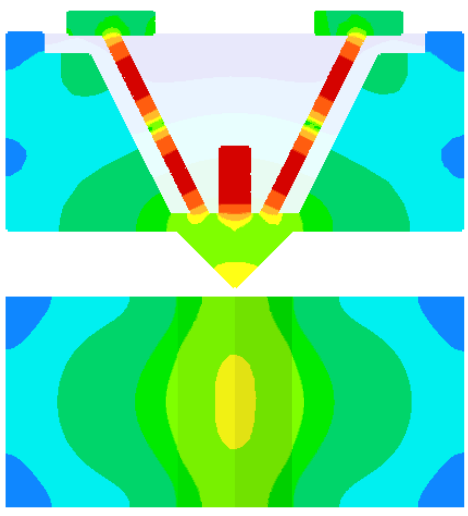

(c) Sound source frequency is $11601 \mathrm{~Hz}$

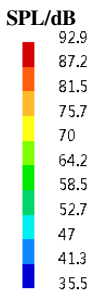

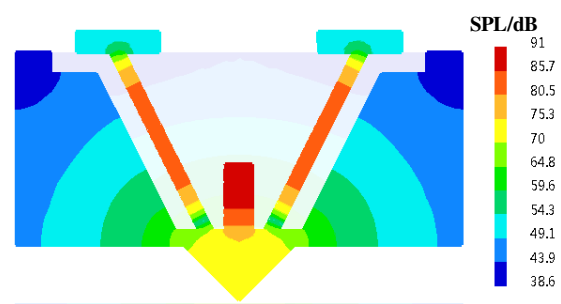

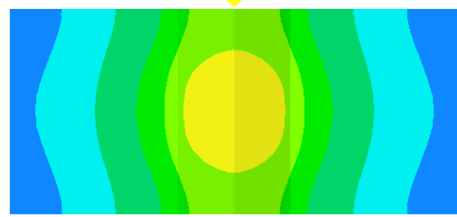

(b) Sound source frequency is $6201 \mathrm{~Hz}$

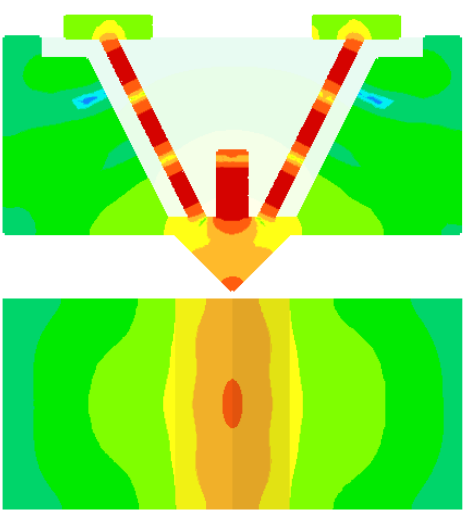

(d) Sound source frequency is $17201 \mathrm{~Hz}$

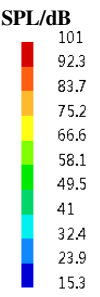

Fig.4 The distribution of sound pressure with different frequencies

Usually, the distributions of sound pressure in space are significantly influenced by the frequency of sound waves. Fig. 4 is the simulation result of distributions of sound pressure when the sound frequencies are $2001 \mathrm{~Hz}, 6201 \mathrm{~Hz}, 11601 \mathrm{~Hz}$ and $17201 \mathrm{~Hz}$, respectively. In Fig.4, the distributions of sound waves are expressed by sound pressure levels (SPL). Sound pressure level is calculated with equation (7).

$$
L_{p}=20 \lg \frac{P_{s}}{P_{r e f}} \mathrm{~dB}
$$

where, $L_{p}$ is the sound pressure level, and the unit of it is $\mathrm{dB} ; P_{s}$ is the sound source pressure; $P_{r e f}$ is the reference sound pressure, and the value of it is $2 \times 10^{-5} \mathrm{~Pa}$. Based on Tab.1, the sound source pressure on inlet boundary $\mathrm{S}$ is $1 \mathrm{~Pa}$, so the SPL of it approximately is $94 \mathrm{~dB}$. 
As shown in Fig.4a, when the sound wave frequency is $2001 \mathrm{~Hz}$, the higher SPL only appears at the area within the center hole. And the SPL that received by two microphones are comparatively low (37dB). While as shown in Fig.4b-d, with the increasing of sound waves frequency, the SPL in the whole space accordingly increase. Moreover, the sound pressure in the two small holes demonstrates obviously periodical distribution. For example, in Fig.4c, there are two periods in the two small holes. While in Fig.4d, there are three periods. It is because with the increasing of frequency the wavelength of sound waves become small. From Fig.4b-d, it can be found that the highest SPL is generated in the middle of the two holes, other than in the outlet boundaries. Therefore, to acquire relatively high SPL on the outlet boundaries, it is particularly important to select the suitable frequency of sound waves.

It can be found that the gradient of sound pressure on the weld seam surface (top views of Fig.4) is increased with increasing of frequency. When the frequency increases to $11601 \mathrm{~Hz}$ (Fig.4c) and $17201 \mathrm{~Hz}$ (Fig.4d), the sound pressure shows an elliptical distribution, and the major axis of ellipse is parallel to the weld seam. Fig.4 also shows that the distributions of sound pressures are symmetrical with central line of weld seam. It is because in the simulation process the sound source locates at the center of weld seam.

If the sound wave that generated on the inlet boundary S is taken as input variable, and the SPL of sound wave that received by microphones on the boundaries of $T_{1}$ and $T_{2}$ are taken as output variables, then the frequency response of the designed sensor system could be acquired with simulating method. Fig.5 shows the simulating result.

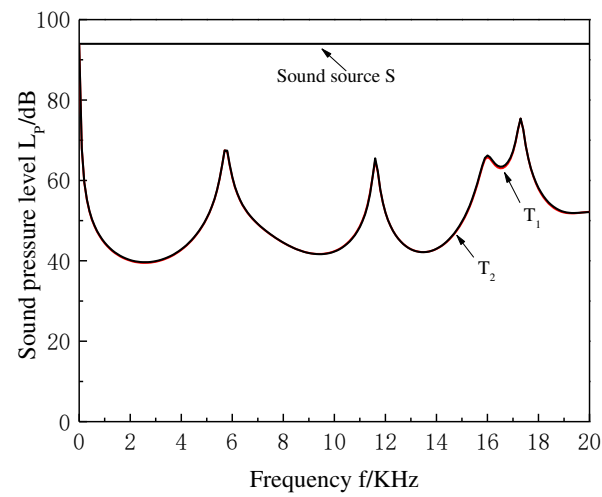

Fig.5 The frequency response of the designed sensor

From Fig.5, it is observed that the SPL on the outlet boundaries $T_{1}$ and $T_{2}$ are nearly same and both change periodically with the increasing of frequency, and the period approximates $6000 \mathrm{~Hz}$. Combined with the results of Fig.4, the frequency of sound wave in the range of $16-18 \mathrm{KHz}$ probably is suitable for sensing process.

3.2.2 The influence of relative position between acoustic sensor and weld seam
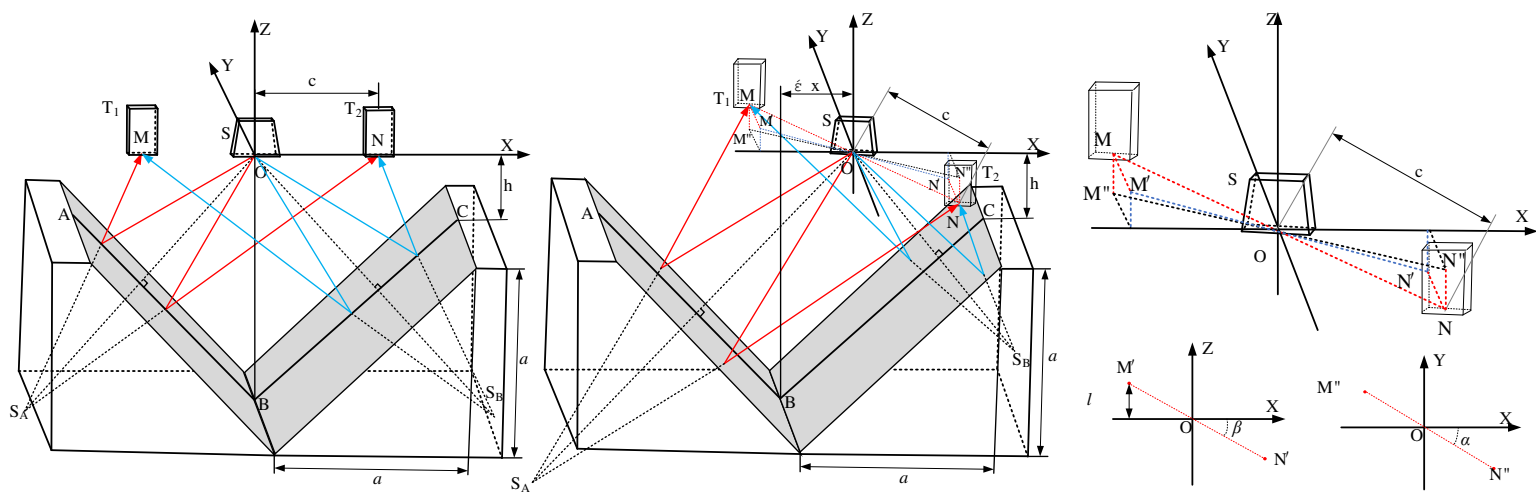

(a) Sound source in the center of weld seam

(b) Sound source at the right side of weld seam

Fig.6 The relative position of acoustic sensor with weld seam 
The relative position between acoustic sensor and weld seam is shown in Fig.6. The line ABC is a V-groove weld seam, and $\mathrm{S}$ is a sound source. $\mathrm{T}_{1}$ and $\mathrm{T}_{2}$ are two microphones that mounted on the two sides of sound source symmetrically. Fig.6a shows the sound source in the center of weld seam. Fig.6b shows the sound source at the right side of weld seam, and the deviation of it in $\mathrm{X}$-axis is $\Delta x$, and rotating angles of it around $\mathrm{Z}$ and $\mathrm{Y}$ axis are $\alpha$ and $\beta$, respectively.

(a)The influence of weld seam deviation $\Delta x$

The purpose of designed acoustic sensor is to sense the deviations of weld seam. Therefore, the influence of weld seam deviation on the distribution of sound pressure is simulated and the results are shown in Fig.7. In this figure, the frequency of sound wave is set as $17.5 \mathrm{KHz}$. It is observed that the distributions of sound pressure in the four sub-figures of Fig.7 are not symmetrical with central line of weld seam. The SPL in the right hole is obvious larger than the SPL in the left hole. Moreover, with the increasing of deviations the SPL in the right-hole increases accordingly, while SPL in the left-hole decreases gradually.

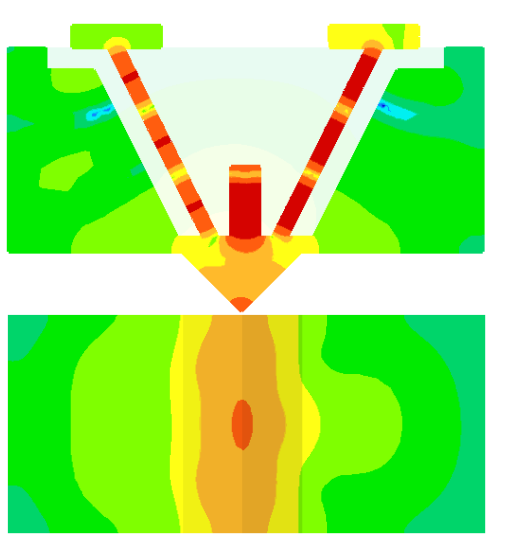

(a) The deviation is $0.5 \mathrm{~mm}$

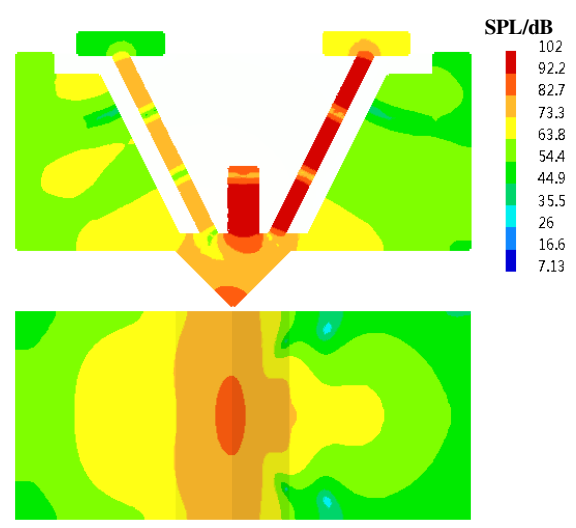

(c) The deviation is $1.5 \mathrm{~mm}$
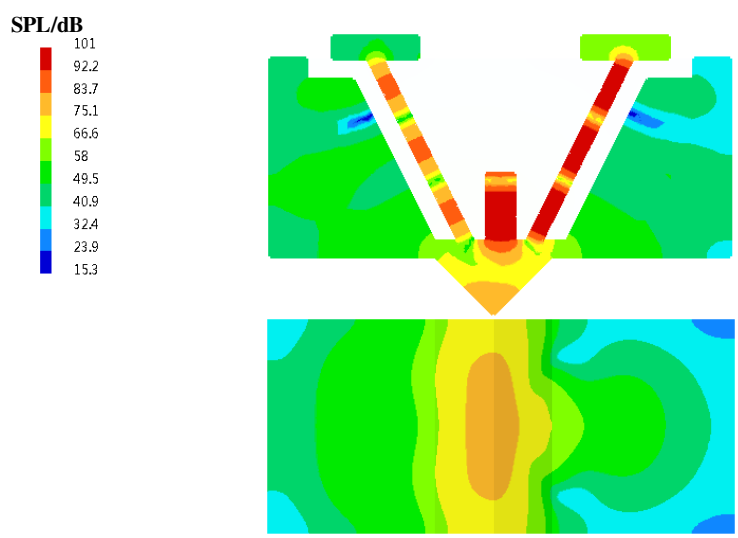

(b) The deviation is $1.0 \mathrm{~mm}$
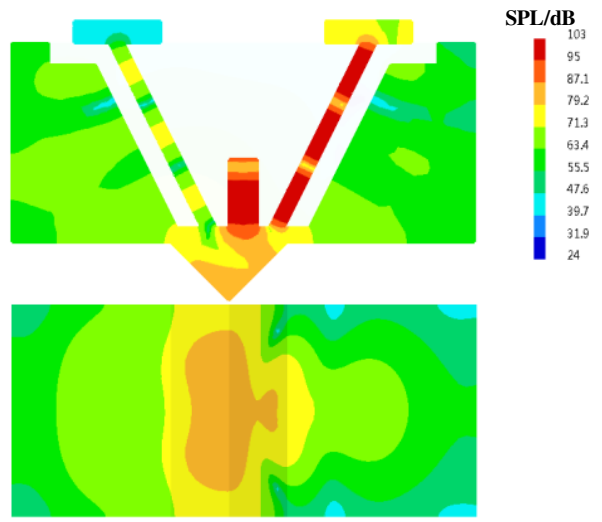

(d) The deviation is $2.0 \mathrm{~mm}$

Fig.7 Distributions of sound pressure under different deviations

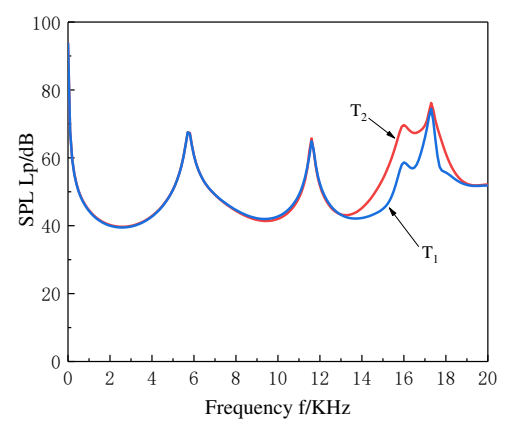

(a) The deviation is $0.5 \mathrm{~mm}$

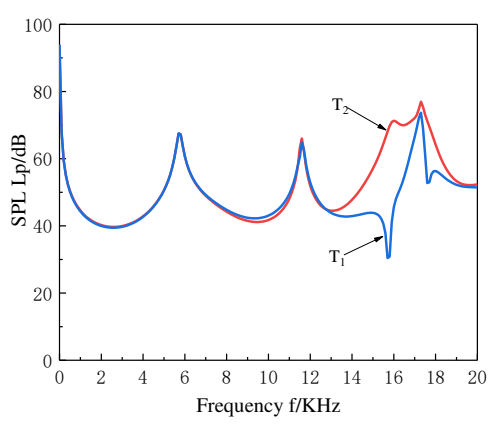

(b) The deviation is $1.0 \mathrm{~mm}$

Fig. 8 The frequency response of designed sensor under different deviations 
Fig.8 shows the frequency response of the designed sensor system when the deviations of weld seam are $0.5 \mathrm{~mm}$ and $1.0 \mathrm{~mm}$. From Fig.8, it is found that the $S P L$ of $T_{1}$ and $T_{2}$ are same when the frequency less than $13 \mathrm{KHz}$. It manifests that in this frequency range the designed sensor cannot detect the deviation of weld seam. When the frequency larger than $13 \mathrm{KHz}$, the SPL of $\mathrm{T}_{2}$ obviously larger than the SPL of $\mathrm{T}_{1}$. To further study the changes of SPL with the deviations of weld seam, the SPL differences of $T_{1}$ and $T_{2}$ are calculated out with a subtract operation. Under different deviation conditions, the SPL differences in the frequency range of 13-19KHz are shown in Fig.9.

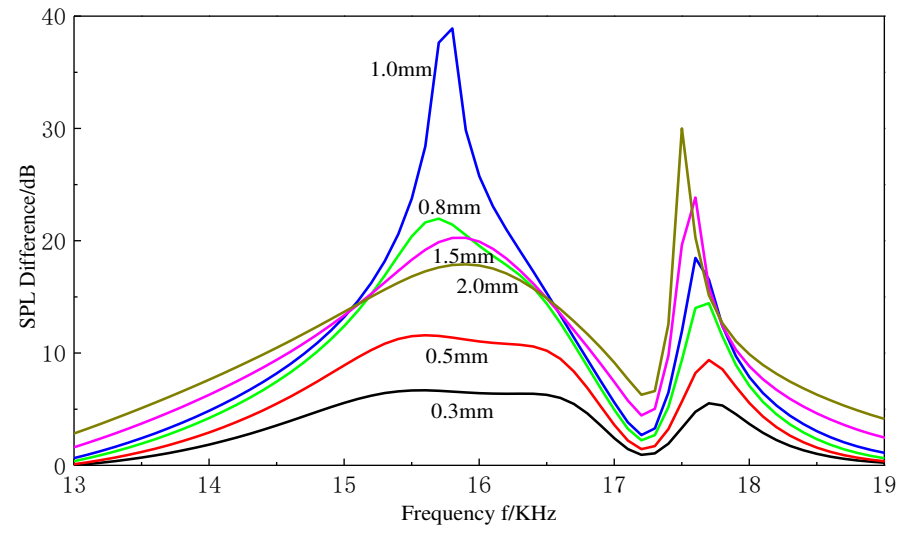

Fig.9 SPL difference of sound waves that received by two microphones under different deviations

As shown in Fig.9, the deviations of weld seam are set as $0.3 \mathrm{~mm}, 0.5 \mathrm{~mm}, 0.8 \mathrm{~mm}, 1.0 \mathrm{~mm}, 1.5 \mathrm{~mm}$ and $2.0 \mathrm{~mm}$. In the frequency range of $15-17 \mathrm{KHz}$, the SPL differences are relatively large. However, the values of these SPL differences are not increased in sequence with the deviations of weld seam. For example, the SPL difference is largest when weld seam deviation is $1.0 \mathrm{~mm}$ other than $2.0 \mathrm{~mm}$. Therefore, the frequency range of $15-17 \mathrm{KHz}$ is not suitable for detecting weld seam deviations. In the frequency range of $17-18 \mathrm{KHz}$, the gaps between these SPL differences are also relatively large, and the values of these SPL differences are increased with the deviations in sequence. Therefore, this frequency range is comparatively suitable for the designed sensor. To find the specific suitable frequency, the changes of SPL differences with the deviations of weld seam are simulated and the results are shown in Fig.10. In this figure, the frequency range is 17.2-17.8KHz.

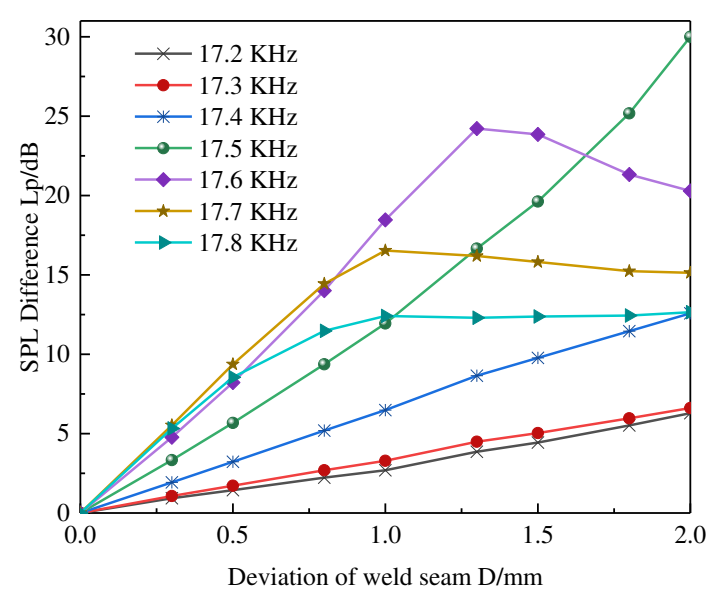

Fig.10 SPL differences with deviation of weld seam $(\mathrm{H}=2.0 \mathrm{~mm})$

From Fig.10, it is observed that when the sound wave frequencies are 17.6, 17.7 and $17.8 \mathrm{KHz}$, the relations between SPL differences and deviations of weld seam are non-linearly. When the sound wave frequencies are $17.2,17.3,17.4$ and $17.5 \mathrm{KHz}$, the SPL differences increase linearly with the deviations of weld seam.

(b) The influence of sensor height $h$

In this section, the sensor height is defined as the distance from the bottom of sensor to the top surface of 
weld plate. Because the sound waves generated by sound source are reflected by weld seam surface firstly, and then received by microphones, so the height of sensor would significantly affect the distributions of sound pressure. The simulation result about the influence of sensor height on the SPL differences is shown in Fig.11.

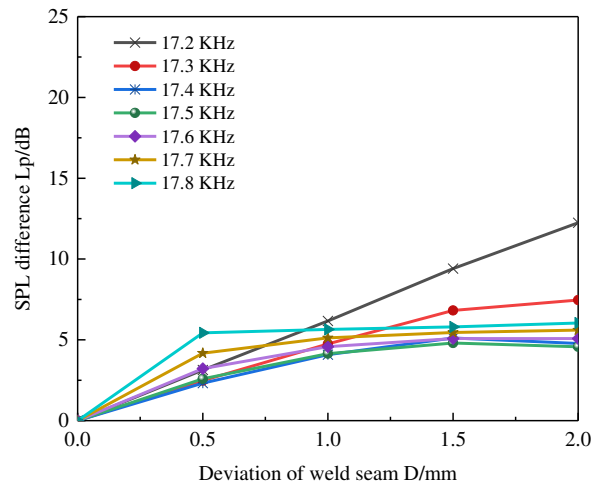

(a) $\mathrm{H}=0.5 \mathrm{~mm}$

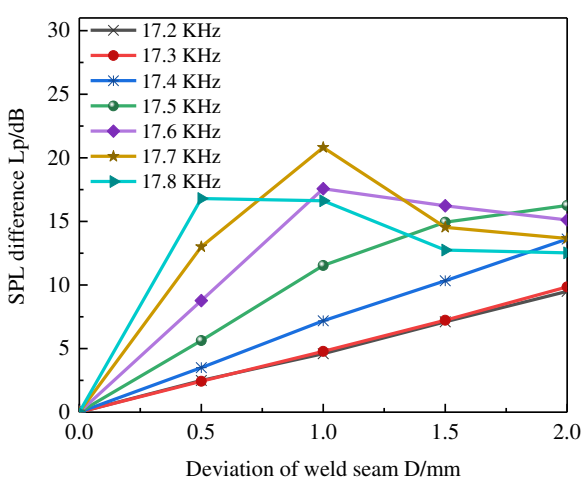

(c) $\mathrm{H}=1.5 \mathrm{~mm}$

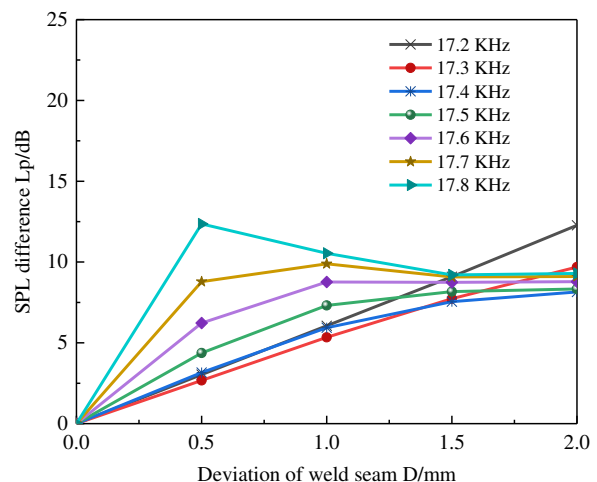

(b) $\mathrm{H}=1.0 \mathrm{~mm}$

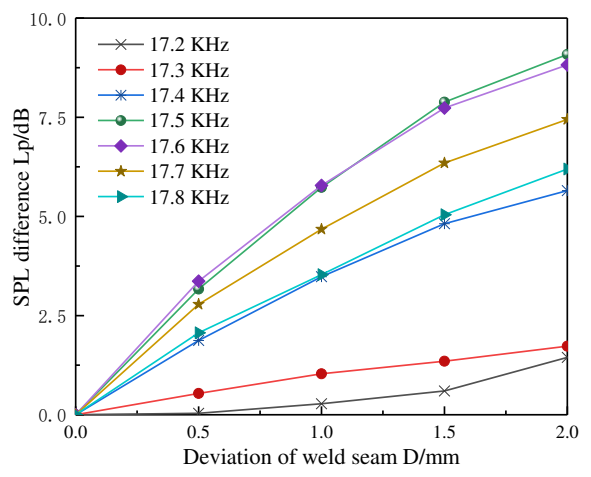

(d) $\mathrm{H}=3.0 \mathrm{~mm}$

Fig.11 SPL differences with heights of sensor

Fig.11 consists of four sub-figures. Each sub-figure represents the changes of SPL difference with the deviation of weld seam under one specific height. The heights of these four subfigures are $0.5 \mathrm{~mm}, 1.0 \mathrm{~mm}$, $1.5 \mathrm{~mm}$ and $3.0 \mathrm{~mm}$, respectively. From Fig.11, it is obvious that the SPL differences in these four subfigures linearly increase with the deviations of weld seam when the frequencies are 17.2 and $17.3 \mathrm{KHz}$. However, for other frequencies the linear relations between SPL differences and deviations are only exist in some of height conditions. It means that the influence of sensor height on the SPL differences is relatively small when the frequencies of sound wave are 17.2 and $17.3 \mathrm{KHz}$. Therefore, $17.2 \mathrm{KHz}$ is selected as the frequency of sound source in this study.

(c) The influence of rotating angle $\alpha$

The rotating angle of sensor around with Z-axis is defined as $\alpha$ in Fig.6. The influence of this angle on the distribution of sound wave is simulated in this section and results are shown in Fig.12 and Fig.13.

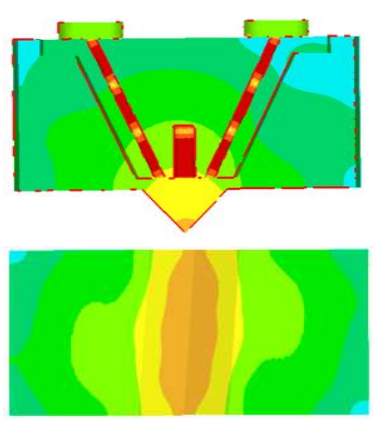

(a) rotating angle $4^{\circ}$
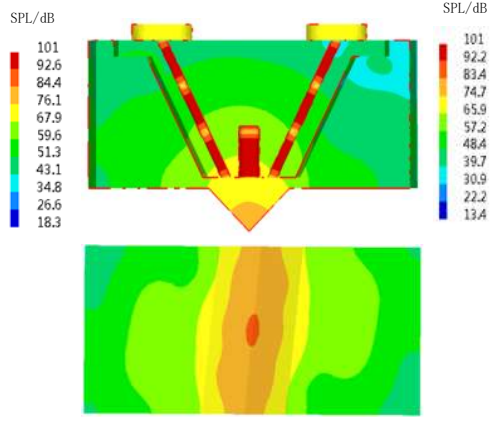

(b) rotating angle $10^{\circ}$

Fig.12 Distributions of sound pressure when rotating angles $\alpha$ are $4^{\circ}$ and $10^{\circ}$ 


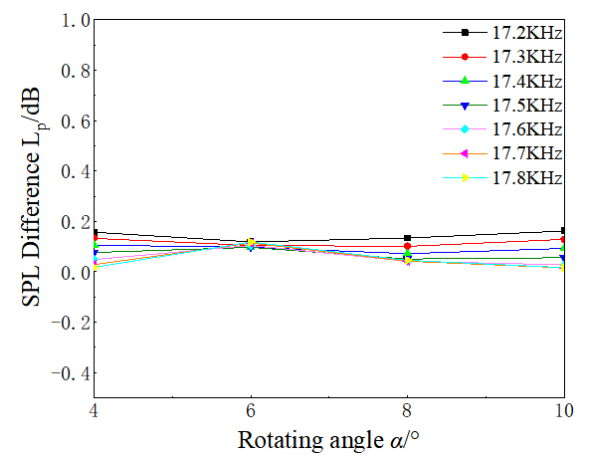

Fig.13 SPL differences with rotating angle $\alpha$ of designed sensor $(\mathrm{H}=2.0 \mathrm{~mm})$

Fig.12 shows the distributions of sound pressure when rotating angles of senor around with Z-axis are $4^{\circ}$ and $10^{\circ}$. It is found that the distributions of sound pressure in these two channels are symmetric. Fig. 13 shows the SPL differences of two microphones with the increasing of rotating angle $\alpha$. It is observed that, under various of frequency, the SPL differences are less than $0.2 \mathrm{~dB}$. This result shows that the influence of rotating angle $\alpha$ on the sensing performance is negligible.

(d) The influence of rotating angle $\beta$

In this section, the rotating angle of sensor around with Y-axis is defined as $\beta$ in Fig.6. The influence of this angle on the distribution of sound wave is simulated in this section and results are shown in Fig.14 and Fig.15.

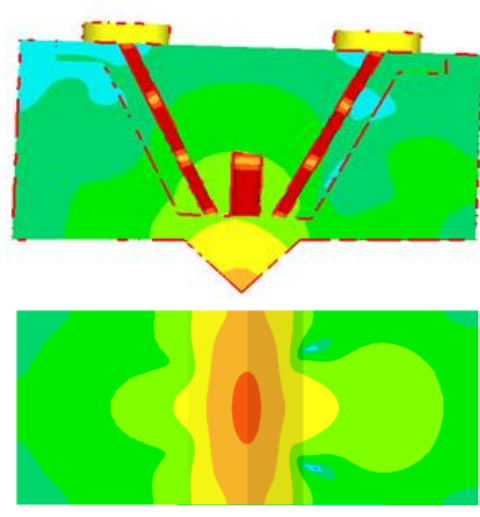

(a) rotating angle $2^{\circ}$
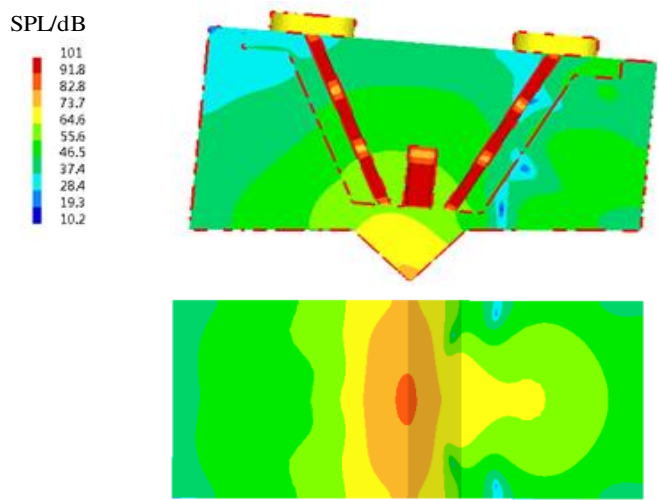

(b) rotating angle $5^{\circ}$

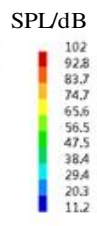

Fig.14 Distributions of sound pressure when rotating angles $\beta$ are $2^{\circ}$ and $5^{\circ}$

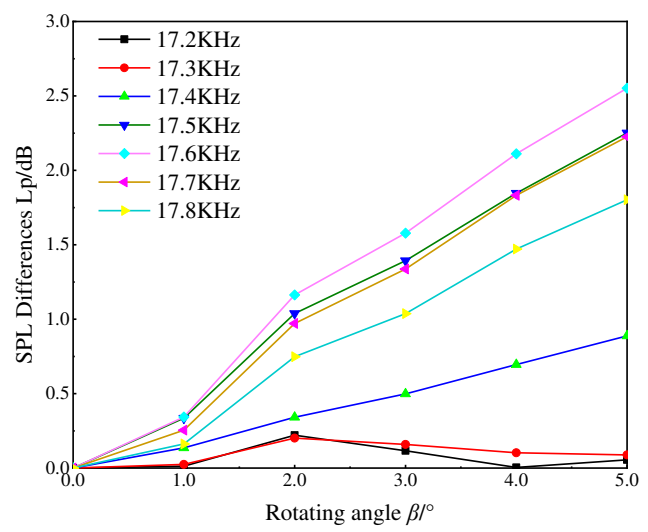

Fig.15 SPL differences with rotating angle $\beta$ of designed sensor $(\mathrm{H}=2.0 \mathrm{~mm})$

Fig. 15 shows the SPL differences of two microphones with the increasing of rotating angle $\beta$. It is observed that, under the frequencies of $17.2 \mathrm{KHz}$ and $17.3 \mathrm{KHz}$, if $\beta$ less than $5^{\circ}$ then the maximum SPL difference less than $0.5 \mathrm{~dB}$. Therefore, the influence of $\beta$ is relatively smaller than $\Delta x$. 


\section{Sensing property analysis of the developed sensor with experiments}

\subsection{Experimental system}

The experimental system is shown in Fig.16. It consists of the developed acoustic sensor, work-piece, moving platform and data acquisition system. The work-piece and acoustic sensor are mounted on the moving platform. The deviation between acoustic sensor and weld seam is set before experiment. A RY-LB woofer is used as a sound source, and a NF WF1974 signal generator was used to supply sinusoidal electricity to this woofer. In the inside of this acoustic sensor, two CRY331 microphones are mounted to receive the sound waves that generated by this woofer, and a high-speed data acquisition card is used to collect the signals of these two microphones. The SPL differences of the sound waves received by two microphones are obtained and analyzed in a computer. During experiments, various frequencies sinusoidal electricity with same amplitudes are supplied to the woofer. Therefore, the sound waves that generated by woofer have different frequencies but same intensities. The performances of RY-LB woofer and CRY331 microphone are shown in Tab.2 and Tab.3, respectively.

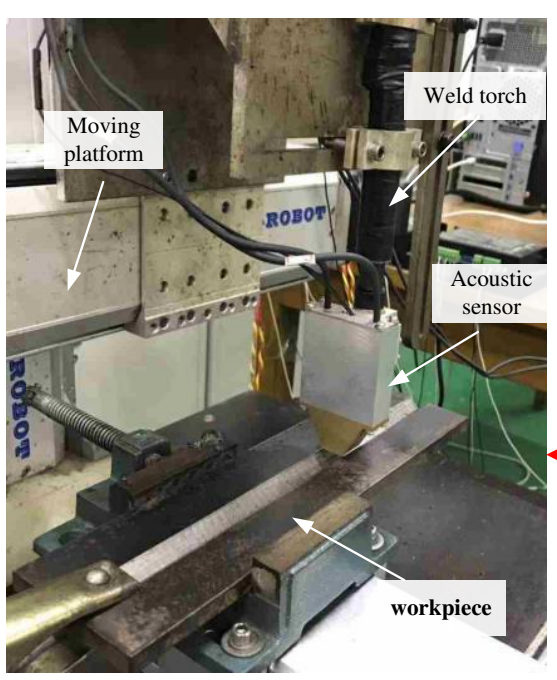

(a) Acoustic sensor and work-piece

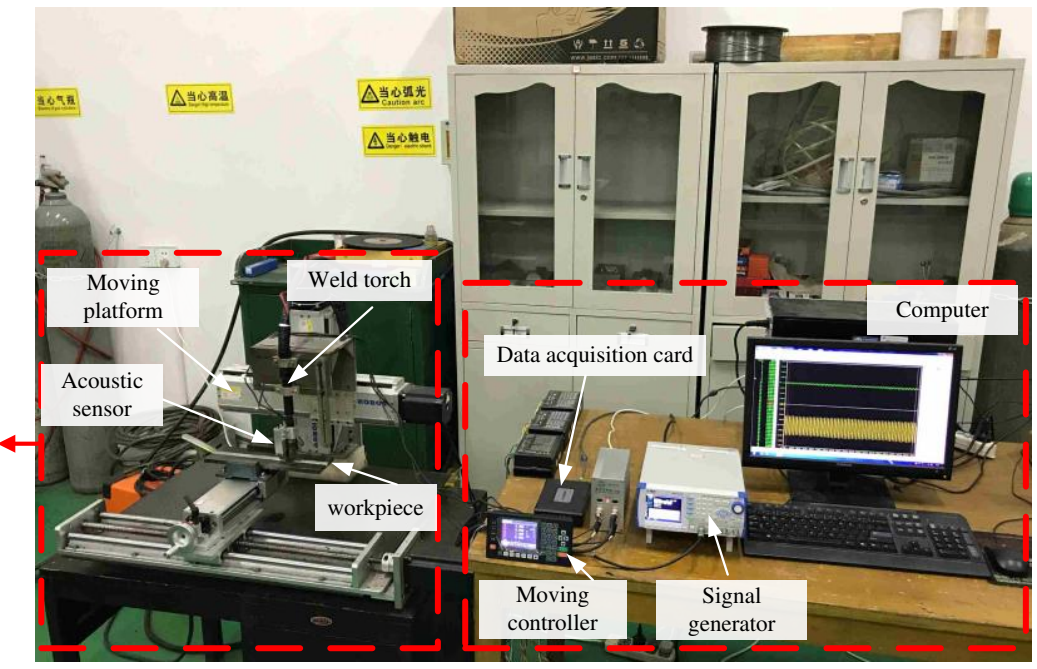

(b) Data acquisition system

Fig.16 Experimental system for sensing property analysis

Tab.2 Performances of RY-LB woofer

\begin{tabular}{|c|c|c|c|c|c|}
\hline Rated power (W) & Rated impedance $(\Omega)$ & Sensitivity (dB/W) & Frequency range $(\mathrm{Hz})$ & $\mathrm{SNR}(\mathrm{dB})$ & Directivity \\
\hline 2 & 8 & 95 & $0-20000$ & 90 & omnidirectiona \\
\hline \multicolumn{6}{|c|}{ Tab.3 Performance of CRY331 microphone } \\
\hline \multicolumn{2}{|c|}{ Sensitivity (mV/Pa) } & esponse frequency $(\mathrm{Hz})$ & Polarization voltage (V) & \multicolumn{2}{|c|}{ Linearity range (dB) } \\
\hline \multicolumn{2}{|c|}{12.5} & $3.15-20000$ & 95 & \multicolumn{2}{|c|}{$0-20000$} \\
\hline
\end{tabular}

Before experiments, the microphones used in this study are calibrated and the sensitivity of them are tested with a standard sound source device. The testing results show that the sensitivity of the microphone used in this study is $12.5 \mathrm{mV}$. Generally, the output signals of microphone are voltage signals. The sound pressure can be acquired through these voltage signals based on the equation (8).

$$
\mathrm{P}_{e}=\frac{V_{e}}{V_{r e f}}
$$

where, $P_{e}$ is the sound pressure; $V_{e}$ is the voltage signals output by microphone; $V_{\text {ref }}$ is the sensitivity of microphone, and it equal to $12.5 \mathrm{mV}$. 


\subsection{The sound waves received by two microphones}

In this section, the frequencies of sound waves generated by woofer RY-LB are $11 \mathrm{KHz}, 14 \mathrm{KHz}, 17 \mathrm{KHz}$ and $19 \mathrm{KHz}$, while the amplitudes of these sound waves are same. Fig.17, Fig.18 and Fig.19 show the sound signals that received by microphone $\mathrm{T} 1$ and microphone $\mathrm{T} 2$ when the deviations of the developed acoustic sensor are set as $0 \mathrm{~mm}, 0.5 \mathrm{~mm}$ and $1.0 \mathrm{~mm}$, respectively. In these experiments, the height of acoustic sensor is set as $2.0 \mathrm{~mm}$.

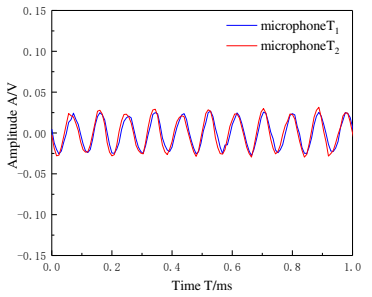

(a)Frequency is $11 \mathrm{KHz}$

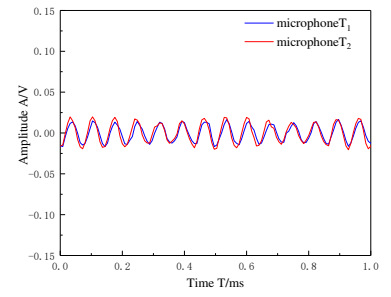

(b)Frequency is $14 \mathrm{KHz}$

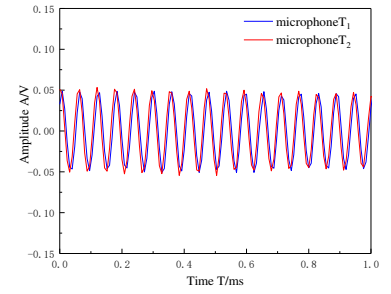

(c)Frequency is $17 \mathrm{KHz}$

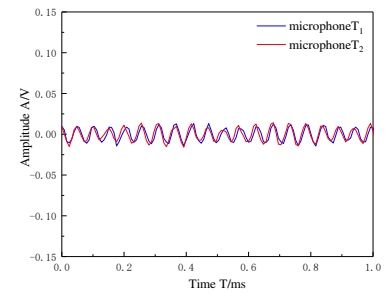

(d)Frequency is $19 \mathrm{KHz}$

Fig.17 Sound signals received by to microphones when deviation is $0 \mathrm{~mm}$

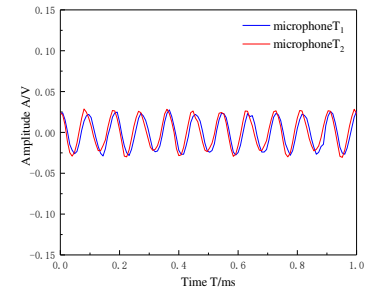

(a)Frequency is $11 \mathrm{KHz}$

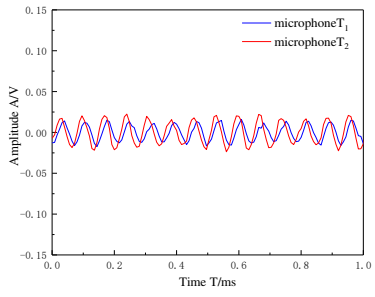

(b)Frequency is $14 \mathrm{KHz}$

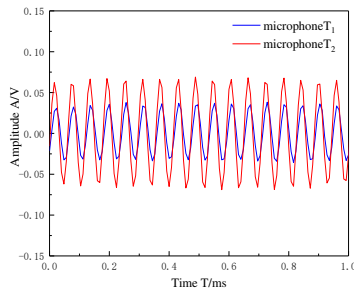

(c)Frequency is $17 \mathrm{KHz}$

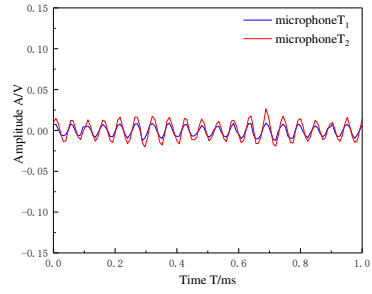

(d)Frequency is $19 \mathrm{KHz}$

Fig.18 Sound signals received by to microphones when deviation is $0.5 \mathrm{~mm}$

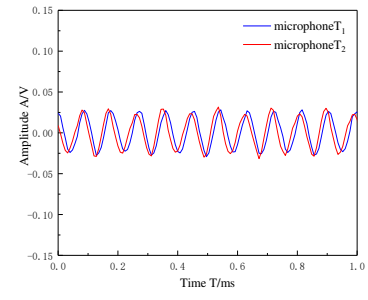

(a)Frequency is $11 \mathrm{KHz}$

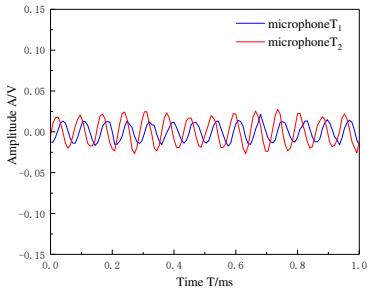

(b)Frequency is $14 \mathrm{KHz}$

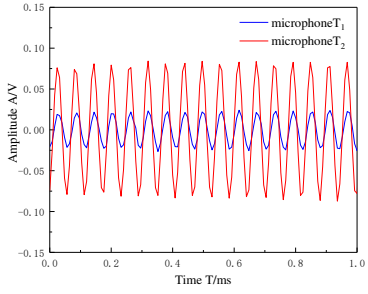

(c)Frequency is $17 \mathrm{KHz}$

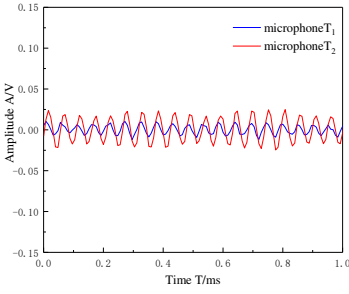

(d)Frequency is $19 \mathrm{KHz}$

Fig.19 Sound signals received by to microphones when deviation is $1.0 \mathrm{~mm}$

The results of Fig.17, Fig.18 and Fig.19 show that, compared to other frequencies, when the frequency is $17 \mathrm{KHz}$, the amplitudes of sound signals that received by these two microphones are relatively high. It manifests that the designed acoustic sensor has a high sensitivity to the frequency of $17 \mathrm{KHz}$. As shown in Fig.17, when the deviation of the designed acoustic sensor is set as $0 \mathrm{~mm}$, the amplitudes of sound signals that received by microphone $\mathrm{T} 1$ and $\mathrm{T} 2$ are nearly same under all frequency conditions. However, as shown in Fig.19, when the deviation is set as $1.0 \mathrm{~mm}$, the amplitude of sound signals that received by microphone $\mathrm{T} 1$ is significantly smaller than $\mathrm{T} 2$ when the frequency is $17 \mathrm{KHz}$. The results manifest that the suitable frequency for the developed acoustic sensor is nearby $17 \mathrm{KHz}$, which is accordant with the results of simulation results in section 3. The SPL differences of two sound signals that received by microphone $\mathrm{T} 1$ and $\mathrm{T} 2 \mathrm{in}$ the frequency range of 12-20KHz are shown in Fig.20.

Fig.20 shows that the SPL differences are relatively high in the frequency range of $16-18 \mathrm{KHz}$. Moreover, when the deviation is large the SPL differences are relatively high. For example, the SPL differences graph of deviation $2.0 \mathrm{~mm}$ are generally higher than other graphs. Fig. 21 shows the influence of the developed sensor heights on the SPL differences. 


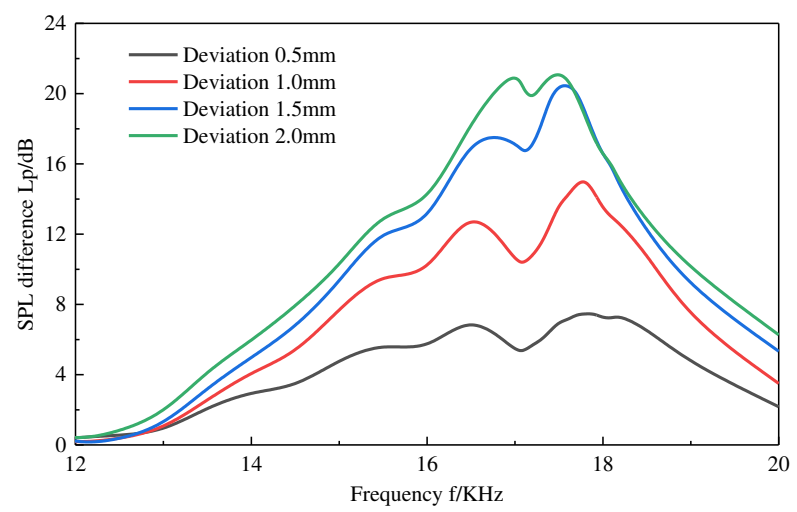

Fig.20 SPL differences of sound signals that received by microphone T1 and T2

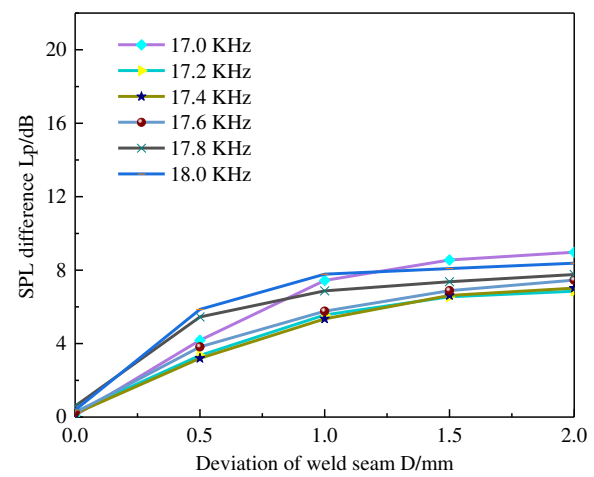

(a) $\mathrm{H}=0.5 \mathrm{~mm}$

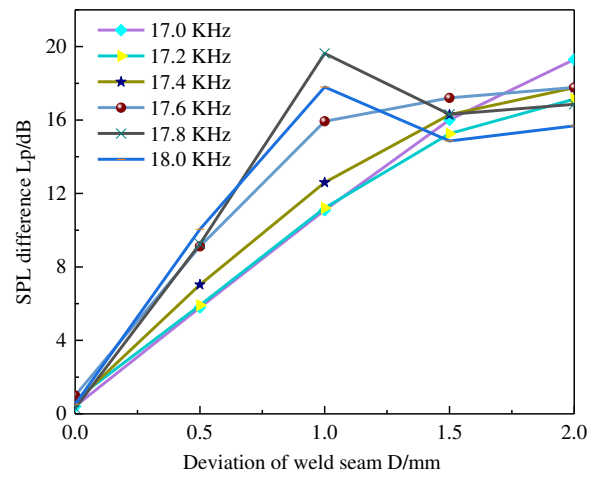

(c) $\mathrm{H}=1.5 \mathrm{~mm}$

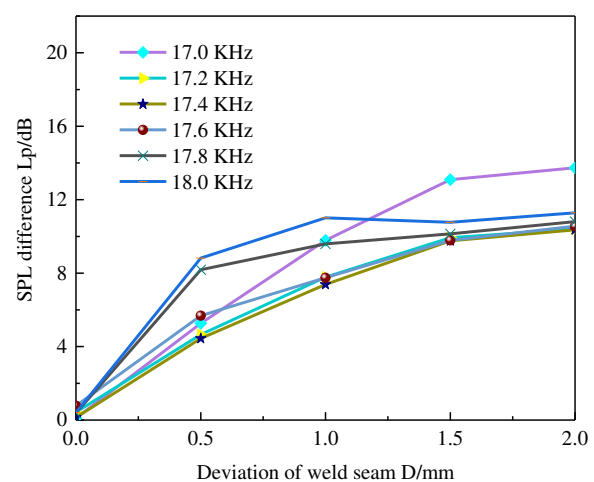

(b) $\mathrm{H}=1.0 \mathrm{~mm}$

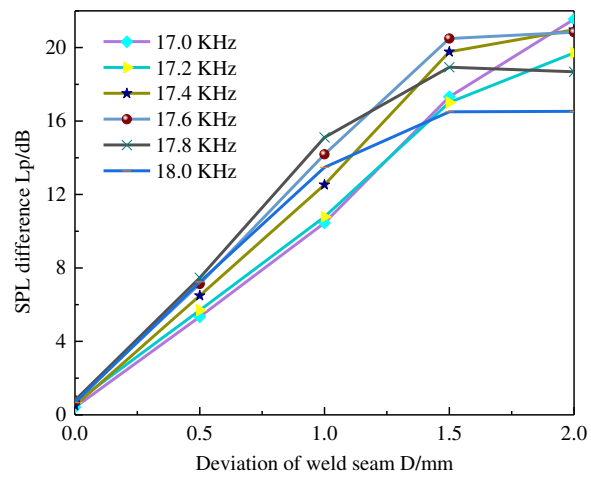

(d) $\mathrm{H}=3.0 \mathrm{~mm}$

Fig.21 SPL differences with deviation of weld seam under various heights

Fig.21 shows that, in general the SPL differences increase with the deviation of weld seam under various heights of sensors. However, the increase is not linear under some of frequencies. For example, as shown in Fig.21c, when the frequencies are $17.6 \mathrm{KHz}, 17.8 \mathrm{KHz}$ and $18.0 \mathrm{KHz}$, the SPL differences are not increase linearly. Compared the four sub-figures of Fig.21, it is found that the SPL differences show a relatively stable linear relations with the deviation of weld seam under various heights when the frequency of sound wave is $17.2 \mathrm{KHz}$ or $17.4 \mathrm{KHz}$.

\section{Deviation sensing of weld seam with the developed sensor}

\subsection{Welding parameters}

To test the sensing performance of the developed acoustic sensor in the detection of weld seam deviation, a series of welding experiments are implemented in this study. In the welding experiments, a NB315F inverter welder that produced by JASCI company is used as the welding power source, and a WF-21 wire feeder is used to feed welding wire with specific speed. The material of base metal is Q-235 mild steel. Argon gas with 
purity of $99 \%$ is used as the shield gas in the welding process and its flow rate is set as $15 \mathrm{~L} / \mathrm{min}$. The welding parameters are adopted in the experiments are shown in Tab.4.

Tab.4 Welding parameters in the experiments

\begin{tabular}{ccccc}
\hline $\begin{array}{c}\text { Welding electricity } \\
\text { current I/A }\end{array}$ & $\begin{array}{c}\text { Welding electricity voltage } \\
\mathrm{U} / \mathrm{V}\end{array}$ & $\begin{array}{c}\text { Flow rate of argon gas } \\
\mathrm{Q} / \mathrm{L} \cdot \mathrm{min}^{-1}\end{array}$ & $\begin{array}{c}\text { Welding velocity V/mm. } \\
\min ^{-1}\end{array}$ & $\begin{array}{c}\text { Deviation of weld seam } \\
\mathrm{D} / \mathrm{mm}\end{array}$ \\
\hline 210 & 21.9 & 15 & 200 & $-3.0,-1.5,-1.0,0,2.0,2.5,4.0$ \\
\hline
\end{tabular}

In the welding experiments, the height of the developed sensor is set as $2.0 \mathrm{~mm}$, and the deviations of weld seam are set as $-3.0 \mathrm{~mm},-1.5 \mathrm{~mm},-1.0 \mathrm{~mm}, 0 \mathrm{~mm}, 2.0 \mathrm{~mm}, 2.5 \mathrm{~mm}$ and $4.0 \mathrm{~mm}$, respectively. Where, the negative deviation means the sensor deviates to the left of the weld seam, and the positive deviation means the sensor deviates to the right of the weld seam. The frequency of sound waves generated by RY-LB woofer is $17.2 \mathrm{KHz}$ in these welding experiments, and the sampling frequency is set as $40 \mathrm{KHz}$ during experiments.

\subsection{The welding sound signals}

In this study, the frequency of sound waves that generated by RY-LB woofer is $17.2 \mathrm{KHz}$, and these sound waves are used to detect the deviations of weld seam. During welding process, the welding arc, shield gas, metal transfer and other sound sources usually emit various frequency sound waves. To extract the sound signals whose frequencies are nearby $17.2 \mathrm{KHz}$, a Butterworth band-pass filter is designed, and the pass-band frequency of the designed filter is set as $17180-17220 \mathrm{~Hz}$. The sound waves after filtered with the designed pass-band filter are shown in Fig.22. The weld seam deviations in this figure are $-3.0 \mathrm{~mm}, 0.0 \mathrm{~mm}, 2.0 \mathrm{~mm}$ and $4.0 \mathrm{~mm}$.

It is observed from Fig.22, the amplitudes of sound signals collected by these two microphones have no obvious difference under various deviations. It means that the sounds generated by other sound sources in the welding process significantly affect the sounds emitted from RY-LB woofer. To detect the deviations of weld seam from the sound signals received by the developed sensor, the SPL of the welding sounds are calculated via equation (8) firstly, and then a limit range filter is designed, and finally the short time energies of the sound waves are obtained. Based on the short time energies of the two microphones, the deviations of weld seam are detected.

The limit range filter is designed as equation (9).

$$
Y_{n}= \begin{cases}X_{n} & \max \left(\left|X_{n}-X_{i}\right|\right) \leq \Delta e \\ \left(\sum_{i=n-l / 2}^{n+l / 2} X_{i}\right) / l & \max \left(\left|X_{n}-X_{i}\right|\right)>\Delta e\end{cases}
$$

where, $Y_{n}$ is the sound signal after filtered; $X_{n}$ is the sound signal before filtered; $l$ is the length of the filter window, $l=100 \mathrm{~ms} ; \Delta e$ is the maximum difference between adjacent data in the sound signals and $\Delta e=3 \mathrm{~dB}$. The sound waves in Fig.22 are disposed with equation (9) and the results are shown in Fig.23.

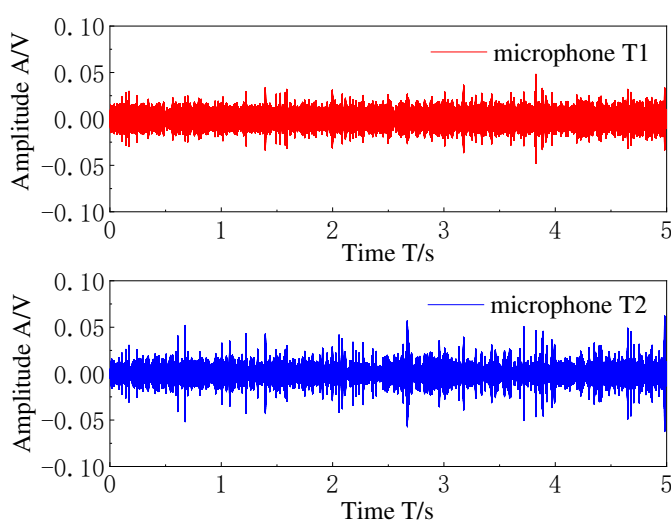

(a) Deviation $-3.0 \mathrm{~mm}$
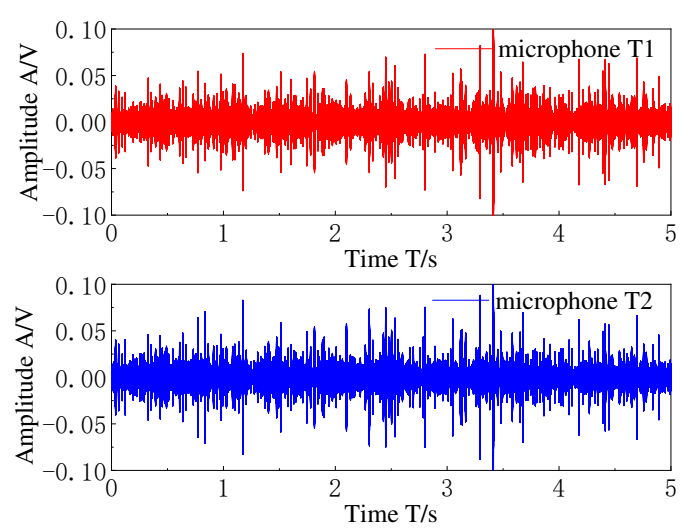

(b) Deviation $0.0 \mathrm{~mm}$ 

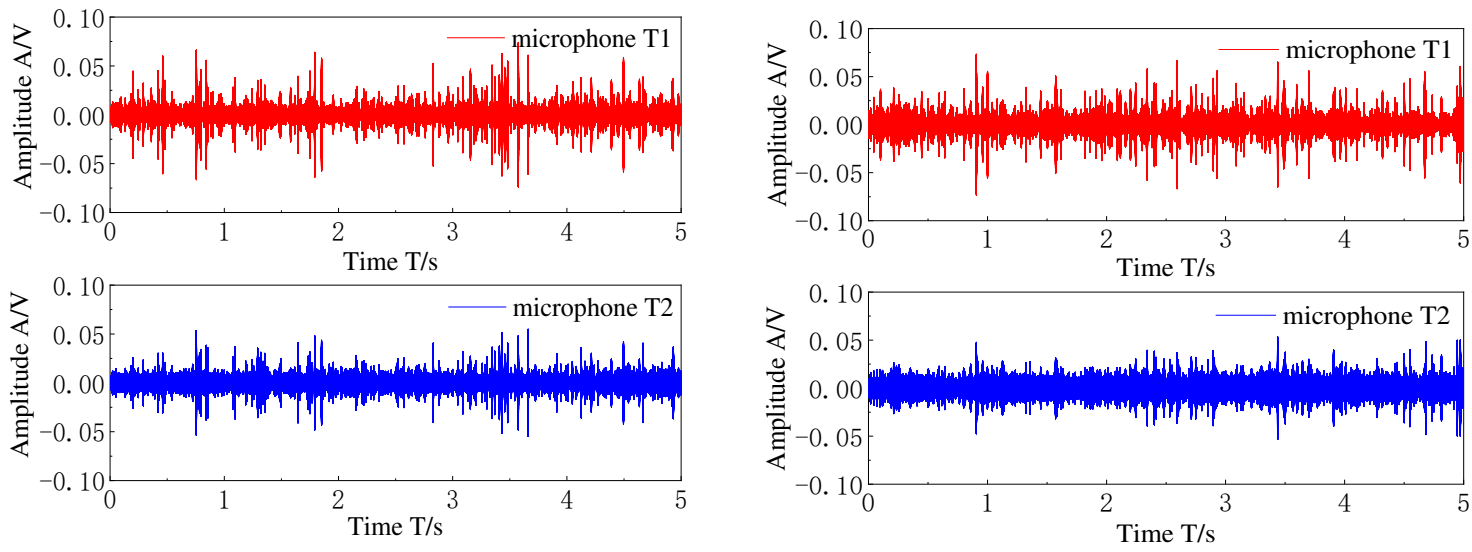

(c) Deviation $2.0 \mathrm{~mm}$

(d) Deviation $4.0 \mathrm{~mm}$

Fig.22 The welding sound signals after filtered by a Butterworth band-pass filter

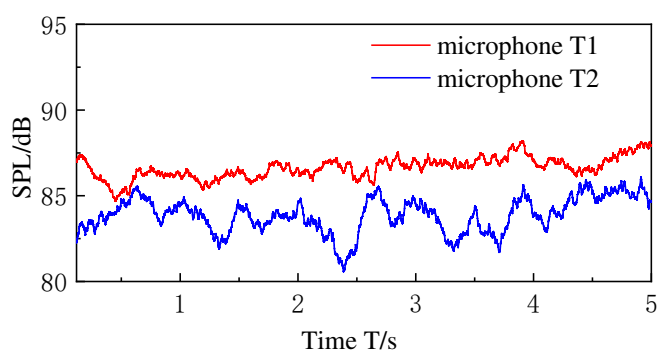

(a) Deviation $-3.0 \mathrm{~mm}$

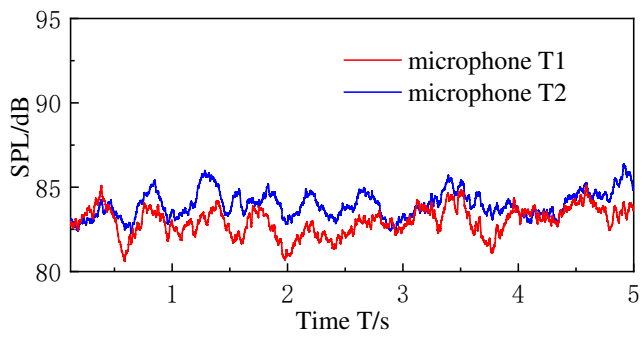

(c) Deviation $2.0 \mathrm{~mm}$

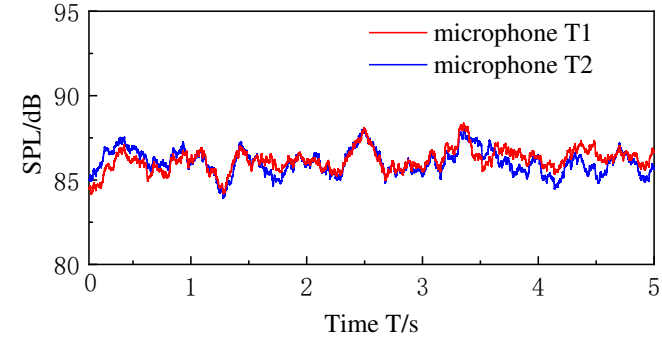

(b) Deviation $0.0 \mathrm{~mm}$

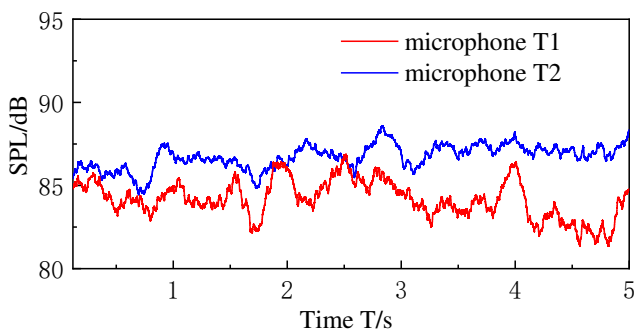

(d) Deviation $4.0 \mathrm{~mm}$

Fig.23 The welding sound signals after filtered a limit range filter

Fig.23 shows that, after disposed by the designed limit range filter, the sound waves that received by two microphones have different amplitudes with the changing of weld seam deviations. When the deviation is $-3.0 \mathrm{~mm}$, as shown in Fig.23a, the amplitudes of sound wave that received by microphone $\mathrm{T} 1$ are apparently lager than microphone T2. However, when the deviation is 0mm, as shown in Fig.23b, the amplitudes of the two sound waves that received by microphone $\mathrm{T} 1$ and $\mathrm{T} 2$ are almost equal. When the deviation increases to $4.0 \mathrm{~mm}$, as shown in Fig.23d, the amplitudes of sound wave that received by microphone $\mathrm{T} 2$ become larger. Therefore, based on the sound waves in Fig.23, the deviations of weld seam probably can be detected.

\subsection{Detection of weld seam deviation}

To acquire the deviation of weld seam from the sound signals, a short time energy method is adopted to dispose the data in Fig.23. In general, in a time range of $80-100 \mathrm{~ms}$, arc sounds are usually considered as stable and time-invariant. The short time energy of the sound signals $E_{n}$ in the $n$th frame can be expressed as equation (10).

$$
E_{n}=\sum_{m=n-(N-1)}^{n}[x(m) \omega(n-m)]^{2}
$$

where $x(m)$ is the original signal of sounds, $\omega$ is a hamming window function and $N$ is the width of it. In this study, the width of hamming window is set as $200 \mathrm{~ms}$, and the overlapping size of the window is set as $100 \mathrm{~ms}$. 
The calculated results are shown in Fig.24.

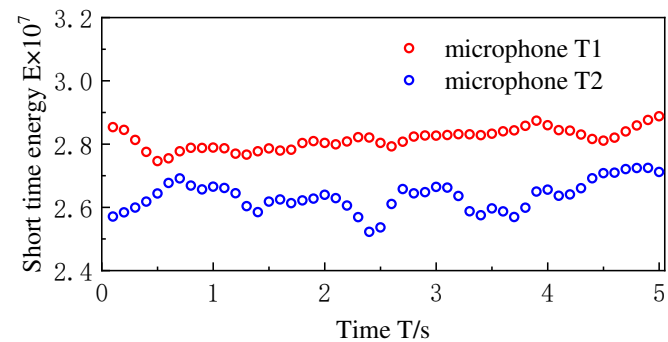

(a) Deviation $-3.0 \mathrm{~mm}$

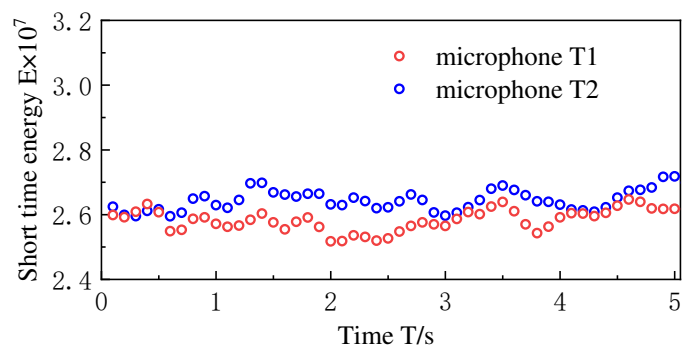

(c) Deviation $2.0 \mathrm{~mm}$

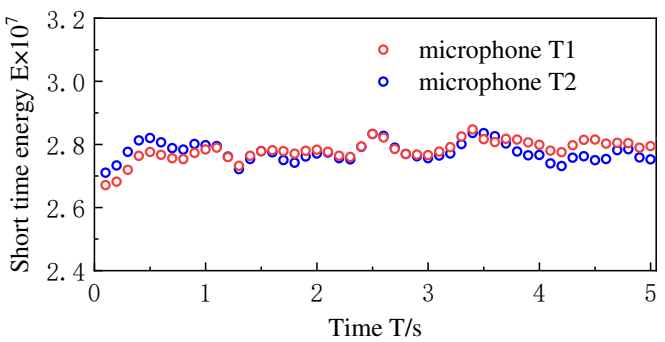

(b) Deviation $0.0 \mathrm{~mm}$

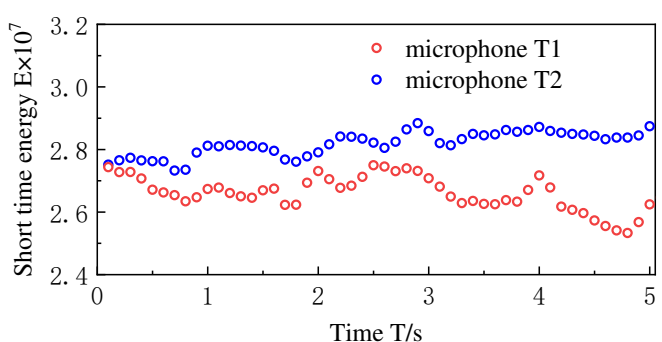

(d) Deviation $4.0 \mathrm{~mm}$

Fig.24 The short time energy of sounds received by designed sensor

In Fig.24a, the short time energies of microphone $\mathrm{T} 1$ are apparently larger than microphone $\mathrm{T} 2$. When the deviation is $0.0 \mathrm{~mm}$, as shown in Fig.24b, the short time energies of microphone T1 and microphone T2 are almost equal. With the increasing of deviation, as shown in Fig.24c and Fig.24d, the short time energies of microphone T2 gradually larger than microphone T1. Therefore, based on the short time energy of the sound signals that received by two microphones the deviations of weld seam could be obtained.

To acquire the sensing property of the developed sensor, the difference values of short time energies of these two microphones are obtained through a subtract operation firstly. And then the mean value and square deviate of the difference value of short time energies in each experiment are calculated. In each experiment process, the deviation of weld seam is set as a specific value, and each experiment repeat five times. The results are shown in Fig.25.

In Fig.25, the horizontal axis is the deviation of weld seam and the vertical axis is the difference of the short time energy of sounds that received by two microphones. It is obvious that a linear relation between the deviations and short time energy differences. This results manifest that the developed acoustic sensor has a potential application in the weld seam detection.

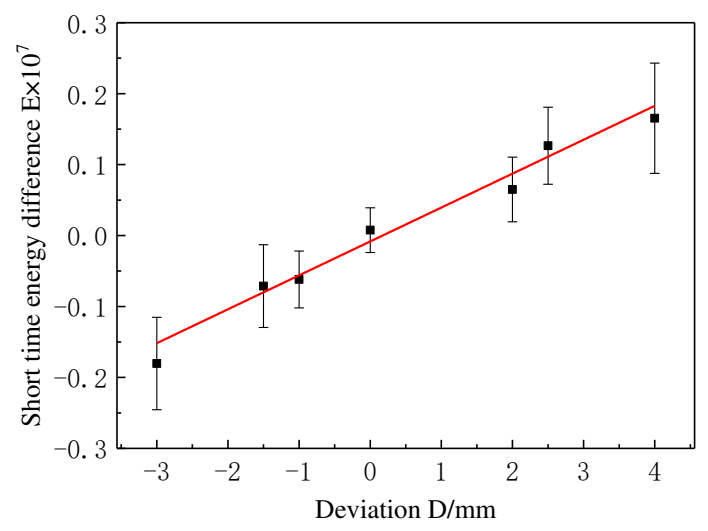

Fig.25 The sensing property of designed sensor

\section{Conclusion}

In this study a novel acoustic sensor is developed based on binaural effect for detecting the V-groove weld 
seam position real-timely. The frequency response of it is studied through numerical simulation method and experiments. It is found that when the frequency of the sound wave is $17.2 \mathrm{KHz}$ the developed sensor has highest sensitivity. A series of welding experiments are implemented and the sound signals are collected by this developed sensor. A limit range filter is designed to dispose the sound signals, and then the short time energy of them are acquired. It is found that the linear relation exists in the short time energy differences of two microphones with deviations of weld seam. The developed acoustic sensor has potential applications in the area of weld seam tracking.

\section{Declarations}

\section{Funding}

This work was supported by National Natural Science Foundation of Shanghai (21ZR1425900).

\section{Conflicts of interest/Competing interests}

The authors declare no competing interests.

\section{Availability of data and material}

Not applicable

Code availability

Not applicable

Ethics approval

Not applicable

\section{Consent to participate}

All the authors listed have participated in the preparation of the manuscript.

\section{Consent for publication}

This manuscript is approved by all the authors for publication. It is the original research that has not been published previously, and not under consideration for publication elsewhere, in whole or in part.

\section{Authors' contributions}

Yanfeng Gao: Conceptualization, Methodology, Writing- Original draft preparation, Funding acquisition.

Jianhua Xiao: Investigation, Data Curation, Visualization.

Genliang Xiong: Writing - Review \& Editing.

Hua Zhang: Supervision, Project administration.

\section{References}

[1] S.G.L. Presern, An intelligent tactile sensor-an on-line hierarchical object and seam analyzer, IEEE Trans. Pattern Anal. Mach. Intell. PAMI-5 (1983) 217-220.

[2] T. Lei, Y. Huang, W. Shao, W. Liu, Y. Rong, A tactual weld seam tracking method in super narrow gap of thick plates, Robot. Comput. Integr. Manuf. 62 (2020). https://doi.org/10.1016/j.rcim.2019.101864.

[3] C.H. Kim, S.J. Na, A study of an arc sensor model for gas metal arc welding with rotating arc Part 1: Dynamic simulation of wire melting, Proc. Inst. Mech. Eng. Part B J. Eng. Manuf. 215 (2001) 1271-1279. https://doi.org/10.1243/0954405011519321.

[4] Y.H. Shi, W.S. Yoo, S.J. Na, Mathematical modelling of rotational arc sensor in GMAW and its applications to seam tracking and endpoint detection, Sci. Technol. Weld. Join. 11 (2006) 723-730. https://doi.org/10.1179/174329306X153196.

[5] S. Kodama, Y. Ichiyama, Y. Ikuno, N. Baba, Arc sensor sensitivity in short circuiting metal active gas welding with high speed torch oscillation, Sci. Technol. Weld. Join. 11 (2006) 25-32. https://doi.org/10.1179/174329306X77867.

[6] Y. Gao, H. Zhang, Z. Mao, Fillet welding seam tracking based on a mobile robot with rotational arc sensor, 
Jixie Gongcheng Xuebao/Journal Mech. Eng. 45 (2009) 64-71. https://doi.org/10.3901/JME.2009.09.064.

[7] S.B. Chen, Y. Zhang, T. Qiu, T. Lin, Robotic welding systems with vision-sensing and self-learning neuron control of arc welding dynamic process, J. Intell. Robot. Syst. Theory Appl. 36 (2003) 191-208. https://doi.org/10.1023/A:1022652706683.

[8] T. Qin, K. Zhang, J. Deng, X. Jin, Image processing methods for V-shape weld seam based on laser structured light, in: Found. Intell. Syst., 2011: pp. 527-536.

[9] Q.Q. Wu, J.P. Lee, M.H. Park, B.J. Jin, D.H. Kim, C.K. Park, I.S. Kim, A study on the modified Hough algorithm for image processing in weld seam tracking, J. Mech. Sci. Technol. 29 (2015) 4859-4865. https://doi.org/10.1007/s12206-015-1033-x.

[10] Z. Jia, T. Wang, J. He, L. Li, K. Wu, Real-time spatial intersecting seam tracking based on laser vision stereo sensor, Meas. J. Int. Meas. Confed. 149 (2020) 106987. https://doi.org/10.1016/j.measurement.2019.106987.

[11] S.K. Lee, S.J. Na, A study on automatic seam tracking in pulsed laser edge welding by using a vision sensor without an auxiliary light source, J. Manuf. Syst. 21 (2002) 302-315. https://doi.org/10.1016/s0278-6125(02)80169-8.

[12] H. Chen, T. Lin, S. Chen, Seam tracking and dynamic process control for high precision arc welding, in: Robot. Welding, Intell. Autom., 2011: pp. 193-201.

[13] Y. Xu, G. Fang, S. Chen, J.J. Zou, Z. Ye, Real-time image processing for vision-based weld seam tracking in robotic GMAW, Int. J. Adv. Manuf. Technol. 73 (2014) 1413-1425. https://doi.org/10.1007/s00170-014-5925-1.

[14] S. Song, H. Chen, T. Lin, D. Wu, S. Chen, Penetration state recognition based on the double-sound-sources characteristic of VPPAW and hidden Markov Model, J. Mater. Process. Technol. 234 (2016) 33-44. https://doi.org/10.1016/j.jmatprotec.2016.03.002.

[15] N. Lv, Y. Xu, S. Li, X. Yu, S. Chen, Automated control of welding penetration based on audio sensing technology, J. Mater. Process. Technol. 250 (2017) 81-98. https://doi.org/10.1016/j.jmatprotec.2017.07.005.

[16] Z. Zhang, G. Wen, S. Chen, Audible Sound-Based Intelligent Evaluation for Aluminum Alloy in Robotic Pulsed GTAW: Mechanism, Feature Selection, and Defect Detection, IEEE Trans. Ind. Informatics. 14 (2018) 2973-2983. https://doi.org/10.1109/TII.2017.2775218.

[17] Y. Gao, J. Zhao, Q. Wang, J. Xiao, H. Zhang, Weld bead penetration identification based on human-welder subjective assessment on welding arc sound, Meas. J. Int. Meas. Confed. 154 (2020) 107475. https://doi.org/10.1016/j.measurement.2020.107475.

[18] H. Lan, H. Zhang, S. Chen, K. Sheng, D. Zhao, Correlation of Arc Sound and Arc-sidewall Position in Narrow Gap MAG Welding, Chinese J. Mech. Eng. 50 (2014) 38-43.

[19] W. Liu, Z. Guan, X. Jiang, L. Li, J. Yue, Sensors and Actuators A : Physical Research on the seam tracking of narrow gap P-GMAW based on arc sound sensing, Sensors Actuators A. Phys. 292 (2019) 205-216. https://doi.org/10.1016/j.sna.2019.04.015.

[20] L. Na, F. Gu, X. Yan-ling, Z. Hui, C. Shan-ben, Z. Ju-jia, Real-time monitoring of welding path in pulse metal-inert gas robotic welding using a dual-microphone array, Int. J. Adv. Manuf. Technol. 90 (2017) 2955-2968. https://doi.org/10.1007/s00170-016-9571-7. 